\title{
Article \\ Research on 16Mo3 steel pipe overlaid with superalloys Inconel 625 using robotized PPTAW
}

\author{
Artur Czupryński ${ }^{1, *}$ \\ ${ }^{1}$ Silesian University of Technology, Poland \\ * Correspondence: dr inż. Artur Czupryński; artur.czuprynski@polsl.pl
}

Received: 15.08.2019; Accepted: 20.10.2019

\begin{abstract}
The article presents research on the development of technology and mechanical properties of a 16Mo3 steel tube overlaid with Inconel 625 nickel superalloy using robotized Plasma Powder Transferred Arc Welding (PPTAW) process. Based on the results of non-destructive, metallographic and microscopic observations, chemical composition, thickness and hardness measurements of overlays optimal technological parameters for working in elevated temperature environment were selected. The performed test has shown the correct structure of the overlay weld without welding imperfections. The examined padding weld was characterized by a dendritic structure with primary crystals growing in the direction of heat removal. It has been stated that in the range of heat input to base material $277 \div 514$ $\mathrm{J} / \mathrm{mm}$, the iron content in the surface zone of $1,5 \mathrm{~mm}$ padding weld ranges from 4 to $5,5 \%$.
\end{abstract}

Key words: surfacing; cladding; PPTAW; Inconel 625; 16Mo3 steel

\section{Introduction}

The development of energy technologies is determined by technical and economic, ecological, legal

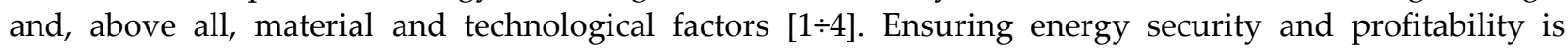
associated with the proper design and application of appropriate construction solutions, the use of materials with high temperature strength and durability, the use of high-level production technology, as well as the reduction of electricity production costs by introducing alternative fuels, such as biomass, garbage, waste, etc. In the construction of installations, machinery and technical equipment used in the processes of production, processing, distribution, storage and the use of energy and fuels, steels dedicated to work at elevated temperatures, creep resistant are used and more often other heat-resistant metal alloys. Parameters and time of safe and efficient operation of construction elements of power, heating and petrochemical devices and installations depend not only on technological and constructional factors, but primarily on the total impact of temperature, pressure and time of operation, as well as on the environment that determines the course of phenomena degrading the properties of metals and alloys.

The use of new alternative fuels is dictated mainly by the reduction of $\mathrm{CO}_{2}$ emissions to the atmosphere. However, the energy obtained from co-incineration in industrial boilers of coal with biomass, waste or garbage is also associated with the fact that flue gases form very aggressive chlorides or fluorides, which leads to very intense corrosion of energy components [4,5]. As a result of high temperature and chemically aggressive gas environment in the boiler's working space, there is a need to provide adequate protection to structural elements exposed to the effects of chemically active gases and chemical compounds. The heat exchanger pipes in waste incineration plants are the most susceptible to the aggressive corrosive environment elements of a power boiler. As a result of operation, these elements undergo a continuous process of destruction, which affects the actual durability and the safe and efficient operation of the entire power unit.

One of the methods to extend the life of boiler components exposed to corrosion and high temperature is to apply layers based on nickel alloys (superalloys). Nickel alloys are characterized by very high wear resistance during operation in particularly difficult working conditions. Characteristics of these materials are: ability to work at temperatures up to $1250{ }^{\circ} \mathrm{C}$, limited sensitivity to variable and dynamic loads, and resistance to highly aggressive corrosive environment of gases, sulfur, nitrogen and carbon [6,7].

Welding technologies on an industrial scale of mechanized, automated and robotic applying of layers and coatings of nickel superalloys still require comprehensive research, contributing to the production of high-quality protection of boiler components, meeting the increasingly demanding 
requirements of the energy industry. The article presents the assessment of the microstructure and mechanical properties of the Inconel 625 nickel super alloy padding weld (EN NiCr22Mo9Nb), applied to a $16 \mathrm{Mo} 3$ grade boiler steel (heat-resistant).

\section{Materials and research methodology}

The tests were carried out on a pipe section with a diameter of $51 \mathrm{~mm}$ and a wall thickness of $5 \mathrm{~mm}$ made of boiler steel grade $16 \mathrm{Mo} 3$ covered from the outside with a single layer of an Inconel 625 nickel superalloy plating applied in the process of Plasma Powder Transferred Arc Welding (PPTAW). The plating layer was not heat treated. The chemical composition of steel and powder for surfacing, according to the manufacturer and the spectrometric analysis carried out are given in tables I $\div$ IV. The mechanical properties of the nickel superalloy weld metal are presented in table III.

Table I. Chemical composition of $16 \mathrm{Mo} 3$ steel according to manufacturer data (Margo)

\begin{tabular}{|c|c|c|c|c|c|c|c|c|c|c|}
\hline \multirow[b]{2}{*}{$\mathrm{C}$} & \multirow[b]{2}{*}{ Si } & \multirow[b]{2}{*}{ Mn } & \multicolumn{4}{|c|}{ Chemical composition, wt.\% } & \multirow[b]{2}{*}{$\mathrm{Cu}$} & \multirow[b]{2}{*}{ Mo } & \multirow[b]{2}{*}{$\mathbf{N i}$} & \multirow[b]{2}{*}{$\mathrm{CE}^{1}$} \\
\hline & & & $\mathbf{P}$ & $\mathrm{S}$ & $\mathbf{N}$ & $\mathrm{Cr}$ & & & & \\
\hline $0.12 \div 0.2$ & $\leq 0.35$ & $0.4 \div 0.9$ & $\leq 0.025$ & $\leq 0.01$ & $\leq 0.012$ & $\leq 0.3$ & $\leq 0.3$ & $0.25 \div 0.35$ & $\leq 0.3$ & 0.52 \\
\hline
\end{tabular}

Note: ${ }^{1)}$ carbon equivalent calculated according to the guidelines of the International Institute of Welding (IIW)

Table II. Chemical composition of $16 \mathrm{Mo} 3$ steel according to spectrometric analysis

\begin{tabular}{cccccccccc}
\hline \multicolumn{1}{c}{ Chemical composition ${ }^{1)}$, wt.\% } \\
C & Si & Mn & P & S & N & Cr & Cu & Mo & Ni \\
\hline 0.17 & 0.34 & 0.58 & 0.022 & 0.008 & 0.01 & 0.26 & 0.19 & 0.32 & 0.28 \\
\hline
\end{tabular}

Note: ${ }^{1)}$ the table shows average values from 5 measurements

Table III. Chemical composition of Inconel 625 superalloy according to manufacturer data (Vöestalpine) of Böhler powder L625 (EN NiCr22Mo9Nb)

\begin{tabular}{|c|c|c|c|c|c|c|c|c|c|c|c|c|}
\hline \multicolumn{13}{|c|}{ Chemical composition, wt. $\%$} \\
\hline $\mathrm{C}$ & Si & Mn & $\mathbf{P}$ & $\mathrm{S}$ & $\mathrm{Cr}$ & Mo & $\mathbf{N i}$ & Co & Ti & Al & $\mathrm{Nb}+\mathrm{Ta}$ & $\mathbf{F e}$ \\
\hline$\leq 0.03$ & $\leq 0.4$ & $\leq 0.5$ & $\leq 0.01$ & $\leq 0.01$ & $21 \div 23$ & $8 \div 10$ & rest & $\leq 1$ & $\leq 0.4$ & $\leq 0.4$ & $3.2 \div 3.8$ & $\leq 5$ \\
\hline
\end{tabular}

Table IV. Chemical composition of Inconel 625 superalloy, Bohler L625 (EN NiCr22Mo9Nb) powder deposit weld according to spectrometric analysis

\begin{tabular}{|c|c|c|c|c|c|c|c|c|c|c|c|c|}
\hline \multicolumn{13}{|c|}{ Chemical composition ${ }^{1)}$, wt.\% } \\
\hline $\mathrm{C}$ & Si & Mn & $\mathbf{P}$ & $S$ & $\mathrm{Cr}$ & Mo & Ni & Co & $\mathbf{T i}$ & Al & $\mathrm{Nb}+\mathrm{Ta}^{2)}$ & $\mathrm{Fe}$ \\
\hline 0.03 & 0.26 & 0.38 & 0.006 & 0.004 & 20.98 & 8.46 & 63.37 & 0.74 & 0.32 & 0.17 & 3.42 & 1.86 \\
\hline
\end{tabular}

Note: ${ }^{1)}$ the table shows average values from 5 measurements, ${ }^{2)}$ no tantalum detected

Table V. Mechanical properties of Böhler L625 (EN NiCr22Mo9Nb) powder deposit weld

\begin{tabular}{|c|c|c|c|c|c|c|c|}
\hline \multirow{3}{*}{$\begin{array}{l}\text { Hardness, } \\
\text { HB } 30\end{array}$} & \multirow{3}{*}{$\begin{array}{l}\text { Yield strength } \\
R_{p 0,2}, \mathrm{MPa}\end{array}$} & \multicolumn{4}{|c|}{ Mechanical properties of the weld metal ${ }^{1)}$} & \multirow{2}{*}{\multicolumn{2}{|c|}{$\begin{array}{c}\text { Impact energy } \\
\text { ISO-V KV, J }\end{array}$}} \\
\hline & & $\begin{array}{l}\text { Tensile strength } \\
\qquad R_{m}, \mathrm{MPa}\end{array}$ & $\begin{array}{c}\text { Elongation } \\
A_{5}, \%\end{array}$ & $\begin{array}{l}\text { Maximum } \\
\text { working } \\
\text { temperature }\end{array}$ & $\begin{array}{l}\text { Modulus of } \\
\text { elasticity }\end{array}$ & & \\
\hline & & & & & & $+20^{\circ} \mathrm{C}$ & $-196^{\circ} \mathrm{C}$ \\
\hline $\begin{array}{c}210 \\
(\leq 240)\end{array}$ & $\begin{array}{c}540 \\
(\geq 460)\end{array}$ & $\begin{array}{c}800 \\
(\geq 760)\end{array}$ & $\begin{array}{c}38 \\
(\geq 35)\end{array}$ & 1000 & $\begin{array}{c}200 \\
(\leq 209)\end{array}$ & 160 & $\begin{array}{c}130 \\
(\geq 32)\end{array}$ \\
\hline
\end{tabular}

Note: ${ }^{1)}$ alloy in the initial state, not heat treated, test temperature $20^{\circ} \mathrm{C}$

The powder before surfacing, according to the manufacturer's instructions, was dried by heating it at $80{ }^{\circ} \mathrm{C}$ for 30 minutes, and then mixing it in a laboratory planetary mixer. The powder prepared in this way was poured into the container of the Durum Durweld 300T PTA device. Prior to surfacing, the surface of the substrate, onto which the nickel super alloy plating layer was applied, was subjected to abrasive blasting in a cabin sandblasting machine using an abrasive medium in the form of sharp-edge ordinary 
brown corundum. This treatment was intended to clean the outer surface of the pipe of impurities such as rust, scale and grease. After this treatment step, the pipe was further brushed to remove possible corundum residues and then chemical treatment with tetrachloroethylene. The substrate prepared in this way was fastened to the surfacing stand additionally equipped with a horizontal turntable with jaws for fixing the pipe, an industrial robot Fanuc R-2000iB, a cooling device ensuring pipe cooling during the process and a plasma surfacing machine handle (Fig. 1).

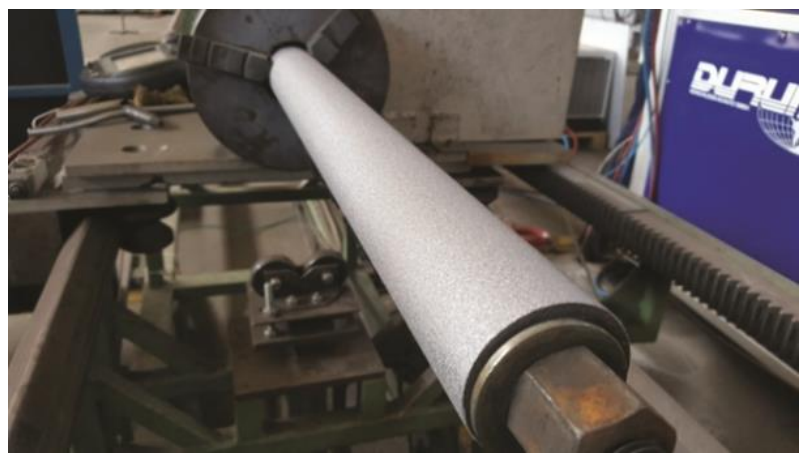

(a)

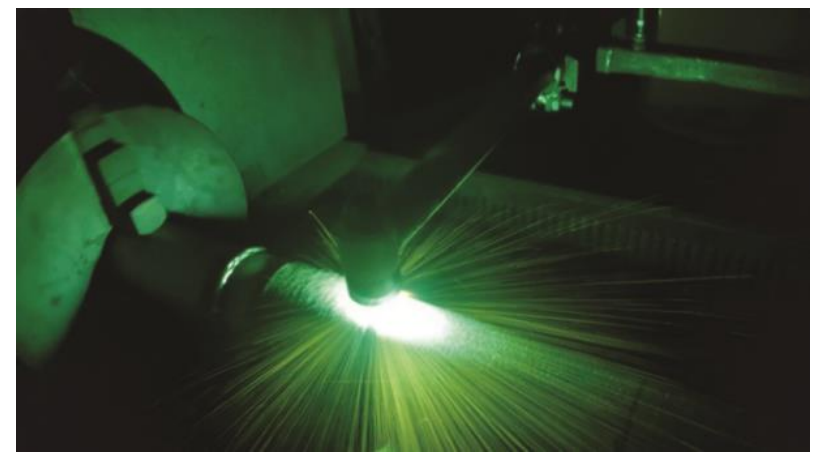

(b)

Fig. 1. View of the plated element with Inconel 625 superalloy: a) before surfacing, b) during the robotic plasma powder transferred arc welding (PPTAW)

The plasma powder transferred arc welding process (PPTAW) was carried out in a wide range of parameters to determine technological guidelines enabling the implementation of layers meeting the following criteria:

- no welding imperfections;

- thickness of a single plating layer of $1.0 \div 1.5 \mathrm{~mm}$;

- depth of the heat affected zone $\leq 1.5 \mathrm{~mm}$;

- iron content in the made plating layer $\leq 7 \%[2,10]$;

- relatively high process efficiency compared to other welding methods.

Based on the initial surfacing tests, the parameters were selected, which were used to produce nine test surface layers. Preliminary assessment of the obtained samples allowed to conclude that the surfacing process was carried out in a manner ensuring the production of surface layers of an acceptable quality level. Optimal parameters of plasma powder transferred arc welding (PPTAW) enabling the production of a suitably high quality plating layer of Inconel 625 nickel superalloy on the external surface of a 16Mo3 boiler steel pipe is shown in table VI. Samples produced with these parameters were subjected to further tests.

Table VI. Parameters of robotic plasma powder transferred arc welding (PPTAW) of Inconel 625 superalloy layer on the outer surface of the $16 \mathrm{Mo} 3$ steel pipe

\begin{tabular}{|c|c|c|c|c|c|c|c|c|c|}
\hline \multirow{2}{*}{ Parameters } & \multicolumn{9}{|c|}{ Sample's designation } \\
\hline & 1 & 2 & 3 & 4 & 5 & 6 & 7 & 8 & 9 \\
\hline Current intensity $I,[A]$ & 160 & 160 & 160 & 170 & 170 & 170 & 190 & 190 & 190 \\
\hline Arc voltage $U,[\mathrm{~V}]$ & 20 & 20 & 20 & 20 & 20 & 20 & 20 & 20 & 20 \\
\hline Surfacing speed $v^{1)},[\mathrm{mm} / \mathrm{s}]$ & 5.23 & 6.54 & 7.85 & 7.85 & 7.85 & 9.16 & 11.78 & 14.39 & 14.39 \\
\hline The amount of powder fed $q$, [g/min] & 17 & 19 & 17 & 15 & 21 & 21 & 21 & 25 & 27 \\
\hline Plasma gas flow rate $Q_{p}{ }^{2}$, $[1 / \mathrm{min}]$ & 1.5 & 1.5 & 1.5 & 1.5 & 1.5 & 1.5 & 1.5 & 1.5 & 1.5 \\
\hline Shielding gas flow rate $Q_{o}^{2}$, $[1 / \mathrm{min}]$ & 12 & 12 & 12 & 12 & 12 & 12 & 12 & 12 & 12 \\
\hline Powder transporting gas flow rate $Q_{s}^{2)},[1 / \mathrm{min}]$ & 4 & 4 & 4 & 4 & 4 & 4 & 4 & 4 & 4 \\
\hline Distance between the nozzle and the surface $l,[\mathrm{~mm}]$ & 5 & 5 & 5 & 5 & 5 & 5 & 5 & 5 & 5 \\
\hline The amount of heat introduced $E_{u}{ }^{3)},[\mathrm{J} / \mathrm{mm}]$ & 642 & 514 & 428 & 455 & 455 & 390 & 339 & 277 & 277 \\
\hline
\end{tabular}

Notes: ${ }^{1)}$ surfacing speed is the resultant speed calculated on the basis of the rotational speed of the pipe and the linear speed of the nozzle moving along the pipe, ${ }^{2)}$ plasma gas, shielding gas and powder transporting gas was argon 5.0 (99.999\%) according to PN-EN ISO 14175 - I1: 2009, 3) the thermal efficiency coefficient for plasma surfacing k=0.6 was taken into account 
Schematic diagram of the plating layer of Inconel 625 nickel superalloy, by surfacing with PPTAW method, on the external surface of a $16 \mathrm{Mo} 3$ steel pipe and the method of bead placement are presented in figures 2 and 3.

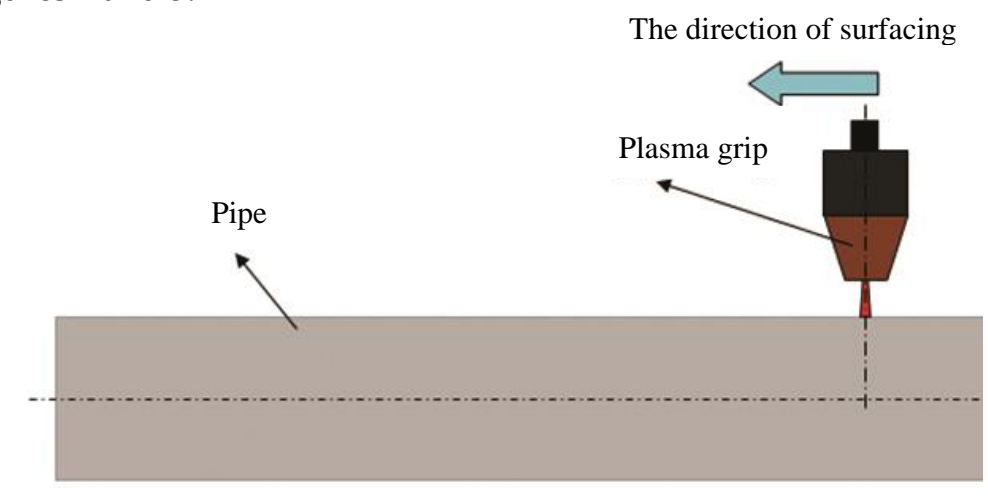

(a)

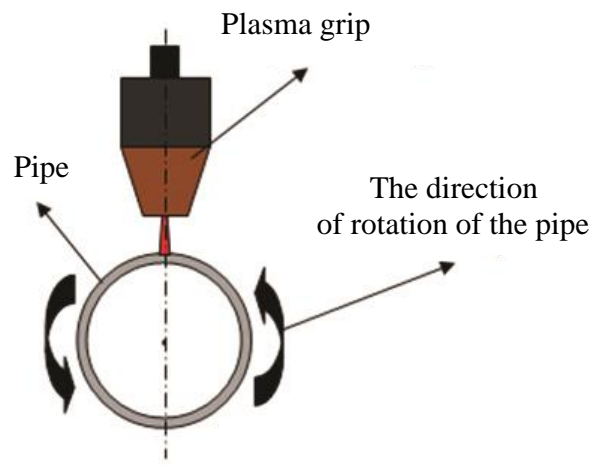

(b)

Fig. 2. Scheme of applying the Inconel 625 superalloy plating layer in the process of plasma powder transferred arc welding on the outer surface of $16 \mathrm{Mo} 3$ steel pipe: a) plasma torch moves during the process, b) pipe rotation during the process

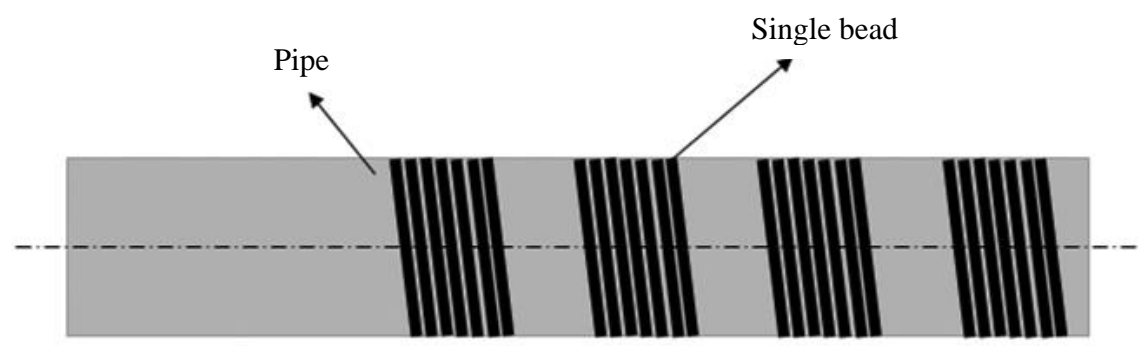

Fig. 3. Scheme of the method of bead placement during the application of Inconel 625 superalloy plating layer obtained in the process of plasma powder transferred arc welding (PPTAW) on the outer surface of $16 \mathrm{Mo} 3$ steel pipe

The obtained samples were subjected to: non-destructive visual (VT) and penetration (PT) tests, microand macroscopic metallographic tests, measurement of the plating layer thickness and HAZ width, microhardness test, testing the chemical composition of the plating layer from the outside and X-ray phase analysis. Visual and penetration tests were carried out in accordance with the guidelines contained in applicable standards, i.e. PN-EN ISO 17637 and PN-EN ISO 3452 respectively. The PT ISO 3452-2 III Cd-2 preparation system was used for penetration tests. Microscopic examinations were carried out on standard metallographic specimens. Samples for observation by means of a light microscope were digested in two stages: the native material of the steel pipe was revealed with a solution of $\mathrm{FeCl} 3 \mathrm{Et}$ (Mi19Fe), and the surface layer of the nickel super alloy by electrochemical digestion with a reagent composition: $20 \mathrm{~cm}^{3} \mathrm{HCl}$, $10 \mathrm{~g} \mathrm{FeCl}_{3}, 30 \mathrm{~cm}^{3}$ distilled water. The etching time was chosen experimentally, individually for each of the materials. Observation and recording of microstructure images was carried out using the stereoscopic SZX7 microscope and an inverted metallographic microscope GX51 from Olympus. The microhardness measurement was carried out using the Vickers method at a load of $300 \mathrm{G}(2.942 \mathrm{~N})$, using the Isotek NEXUS 423D stationary microhardness tester. Chemical composition tests, including iron content, on the surface of the nickel superalloy plating layer were carried out using the Oxford Instruments X-MET8000 portable spectrometer. The X-ray diffraction tests enabling the phase analysis of the welds were carried out using a PANalytical X'Pert Pro diffractometer with a Cu lamp $(\lambda=1.54056)$. The analysis of the tested plating layers was performed in the Bragg-Brentono system.

\section{Non-destructive testing}

After visual and penetration tests on the surface of the selected plating layers obtained by plasma powder transferred arc welding (PPTAW), no welding imperfections such as cracks (100), surface pores (2017), excessive protrusion (503), incorrect edge (505), spatter (602) were found. The layers made were characterized by a high surface smoothness and symmetry of successive overlay weld beads (Fig. 4). 


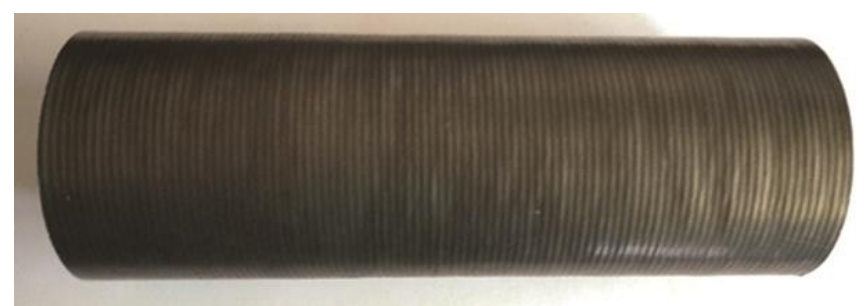

(a)

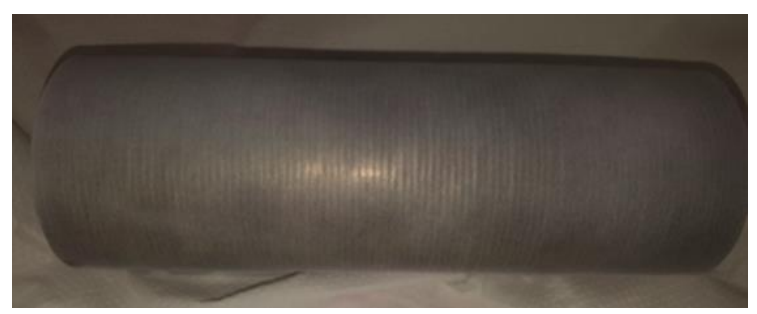

(b)

Fig. 4. View of the Inconel 625 superalloy plating layer: a) directly after process of plasma powder transferred arc welding, b) after removing excess of the penetrant, applying developer and completely drying

\section{Metallographic tests}

Macroscopic tests of the plating layer made of nickel superalloy and native material from boiler steel did not reveal any welding imperfections in the area of fusion lines, such as cracks, lack of fusion and lack of penetration, gas blisters and other such discontinuities. The lack of welding imperfections of this type indicates that the pipe surface is properly prepared and the welding parameters were selected properly. An example of the macrostructure of the connection area of the nickel superalloy plating layer with the steel substrate of the pipe is shown in figure 5. The determined thickness of the nickel super alloy plating layer applied to the surface of the steel pipe was in the range of $1.2 \div 1.6 \mathrm{~mm}$ (Table VII). This value is less

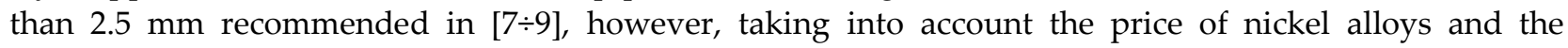
difference in thermal conductivity of nickel alloys and iron alloys, it can be considered as optimal and meeting the set utility criteria. The plate was applied in the form of a single-layer not heat-treated padding weld.

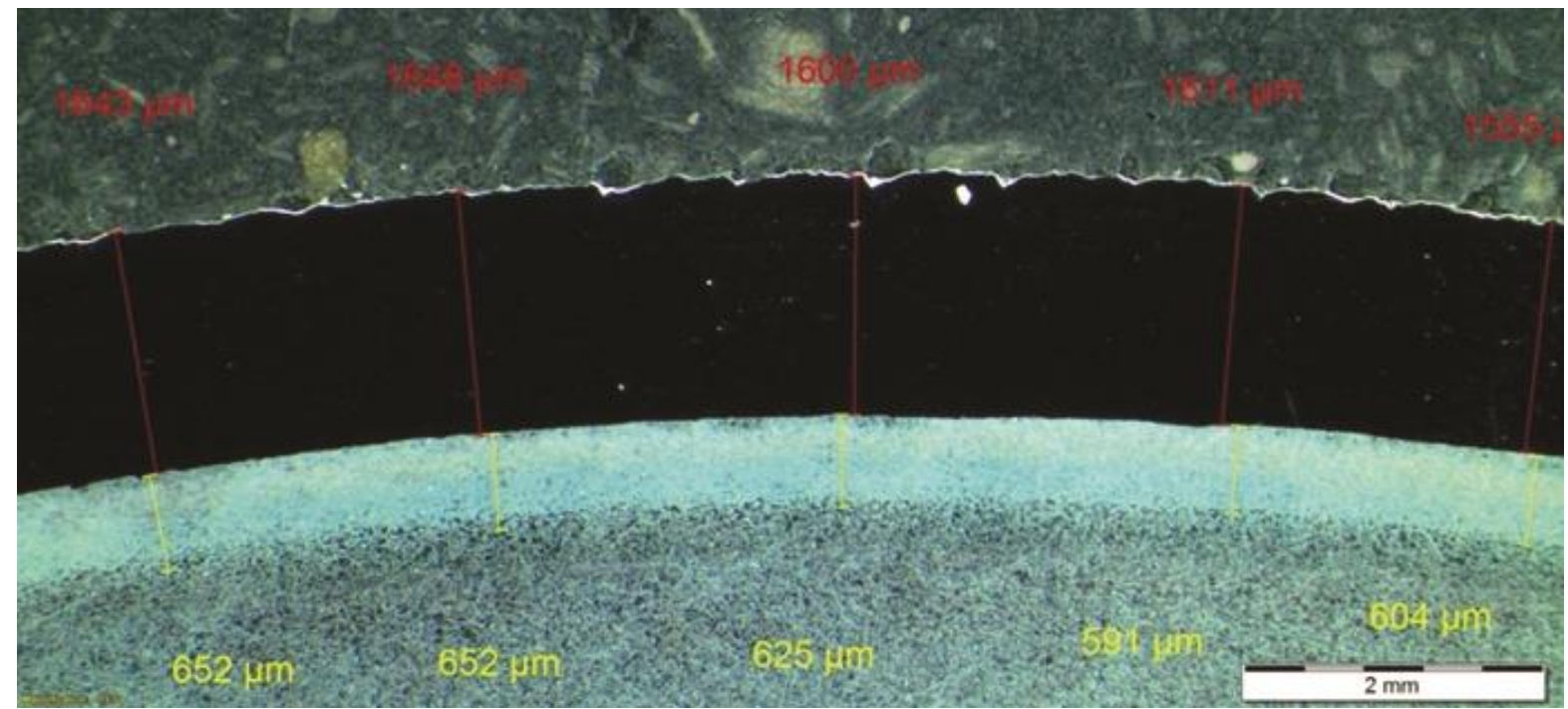

Fig. 5. View of the macrostructure of the Inconel 625 superalloy plating layer obtained in the process of plasma powder transferred arc welding (PPTAW) on the outer surface of $16 \mathrm{Mo3}$ steel pipe, sample 9, mag 10×

Table VII. Average thickness of the plating layers, iron content in the plating layers and HAZ width for samples obtained in process of plasma powder transferred arc welding (PPTAW), table VI

\begin{tabular}{cccccccccc}
\hline Sample's designation & $\mathbf{1}^{\mathbf{1}}$ & $\mathbf{2}$ & $\mathbf{3}$ & $\mathbf{4}$ & $\mathbf{5}$ & $\mathbf{6}$ & $\mathbf{7}$ & $\mathbf{8}$ & $\mathbf{9}$ \\
\hline Average plate thickness $g,[\mu \mathrm{m}]$ & 1275 & 1339 & 1195 & 1132 & 1416 & 1193 & 1292 & 1392 & 1646 \\
Visible HAZ depth $\mathrm{s},[\mu \mathrm{m}]$ & 1252 & 719 & 783 & 795 & 831 & 742 & 715 & 633 & 622 \\
Iron content in the plating layer, $\mathrm{Fe}[\%]$ & 11.8 & 5.2 & 4.2 & 4.8 & 4.0 & 5.5 & 4.5 & 4.2 & 4.0 \\
\hline
\end{tabular}

Note: ${ }^{1)}$ sample not included in subsequent tests due to excessive iron content in the plating layer

Metallographic studies revealed that the native material - 16Mo3 steel, was characterized by a ferriticpearlitic microstructure, typical for this type of steel (Fig. 6d). In the heat affected zone (HAZ), however, a diverse microstructure was observed: from martensitic, through martensitic-bainitic, to ferritic-bainitic microstructure. Obtaining HAZ of low depth in native material was possible following the use of water cooling inside the pipe. The visible HAZ depth varied depending on the amount of heat introduced into the 
native material during the surfacing process. The larger the surfacing heat input used, the greater the depth of structural changes in the native material (Table VII).

The plating layers were characterized by an ordered primary structure typical of an Inconel 625 nickel superalloy. Cells were elongated, dendritic, oriented towards the heat-dissipating surface. The structure was characterized by high homogeneity, absence of gas bubbles, porosity and cracks. Slight grain refinement was observed at the border of the plating layer and the substrate. In each case, the plating layer was minimally embedded in the base material, creating a strictly monolithic connection with the outer surface of the pipe.

One of the basic criteria for cladding with arc welding techniques on the external surface of heat exchanger pipes for waste or biomass combustion boilers is the assessment of iron content in the surface layer of the padding weld. It is recommended that the iron content in the plating layer for automatic or robotic surfacing does not exceed $7 \%$, while for manual surfacing $10 \%[2,10]$. Exceeding the permissible iron content may cause the formation of iron oxides, $\mathrm{Fe}_{2} \mathrm{O}_{3}$, characterized by a layered and discontinuous structure, which promotes their comminution during operation $[2,10]$. The tests showed that the average iron content in the plating layer, excluding sample 1, was in the range of $4.0 \div 5.5 \%$ (Table VII). One of the main factors affecting the required iron content in the plating layer is the amount of heat introduced into the native material during the surfacing process, which according to $[11 \div 14]$ should not exceed $300 \mathrm{~J} / \mathrm{mm}$. In the case of plasma powder surfacing with intensive water cooling inside the pipe, which provided adequate heat dissipation, it is possible to obtain a sufficiently low iron content in the plating layer with the amount of heat introduced below $500 \mathrm{~J} / \mathrm{mm}$.

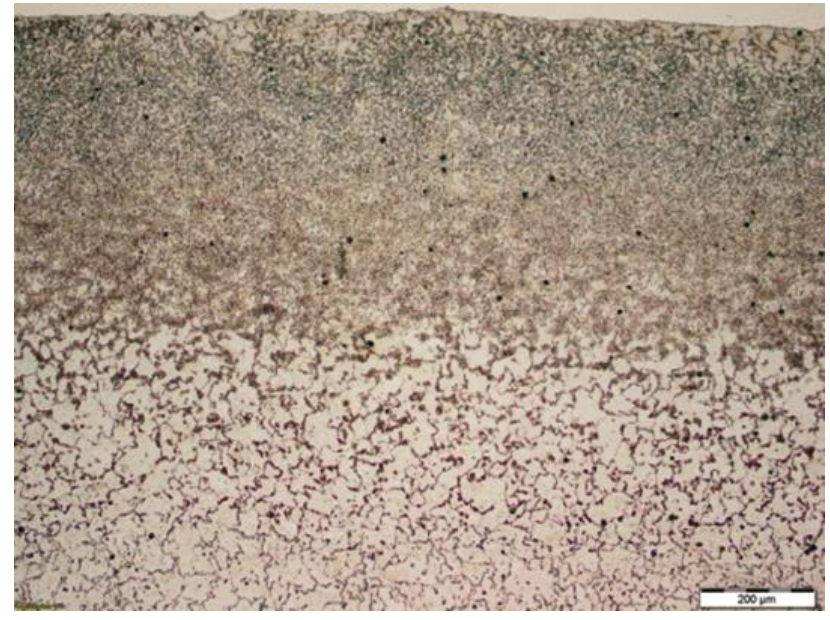

(a)

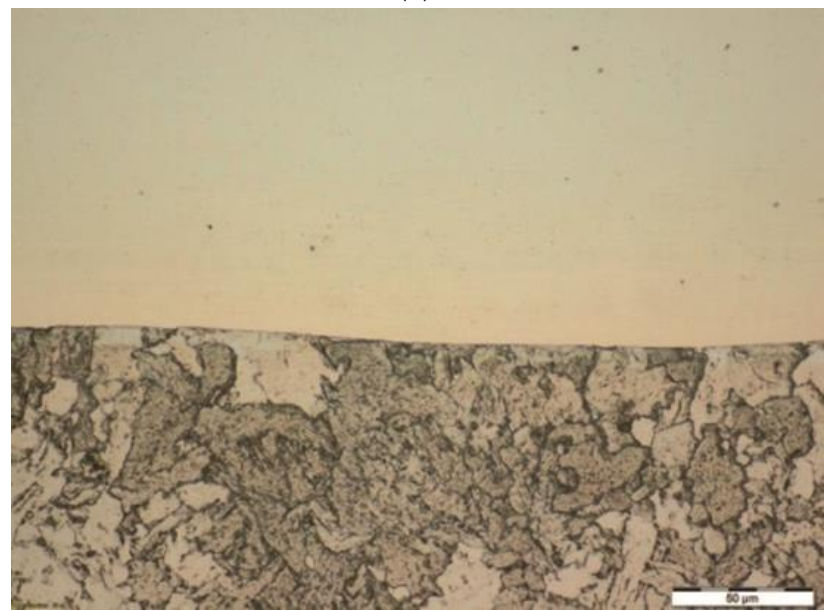

(c)

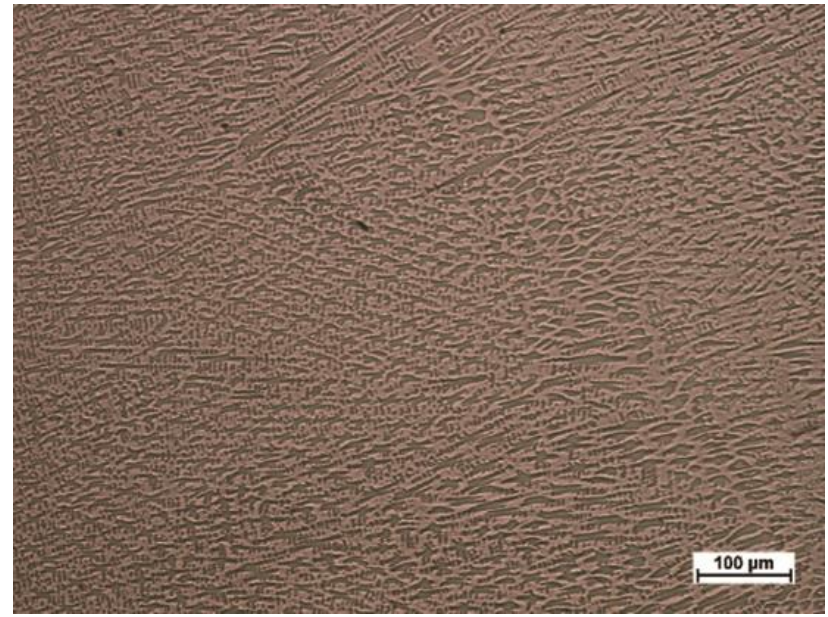

(b)

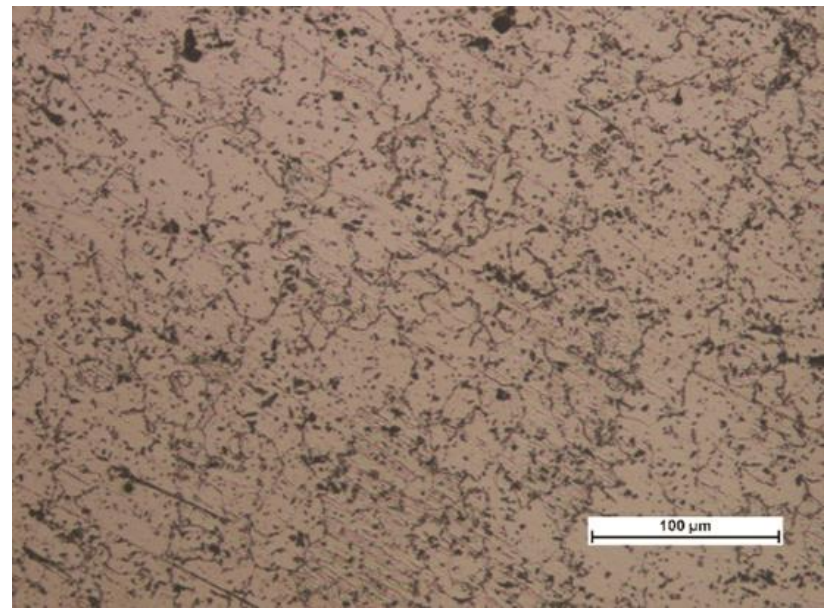

(d)

Fig. 6. View of the microstructure of Inconel 625 superalloy plating layer obtained in the process of plasma powder transferred arc welding (PPTAW) on the outer surface of $16 \mathrm{Mo} 3$ steel pipe, sample 9: a) general view, mag 100x, b) plating layer area, mag 100×, c) HAZ area, mag 500×, d) base material, mag 200×

\section{$X$-ray diffraction testing}

The X-ray diffraction pattern obtained for a single layer of Inconel 625 nickel superalloy plating made using plasma powder transferred arc welding (PPTAW) technology (sample 9) is shown in figure 7. 
The main indications derived from nickel on the diffractogram were found at an angle of $2 \theta=43.66^{\circ}, 50.85^{\circ}$, $75.34^{\circ}, 90.83^{\circ}$ and $96.74^{\circ}$. However, pure nickel indications read from the JCPDS - ICDD database were found at $2 \theta=44.51^{\circ}, 51.85^{\circ}, 76.37^{\circ}, 92.94^{\circ}$ and $98.45^{\circ}$. Therefore, for the tested plating layer, indications corresponding to the phases $\gamma$ (111), $\gamma(200), \gamma(220)$ and $\gamma$ (311) occur at slightly higher values of $2 \theta$. The difference in the network parameter may be due to the presence of alloying elements in the solid Inconel 625 solution and the precipitation of reinforcing phases. In the plating layer, the Ni-Si phase with network parameters (101), (111), (120), (121), (301) and (310) was also identified. In addition, no other phase with pure nickel network parameters was found in the plating layer.

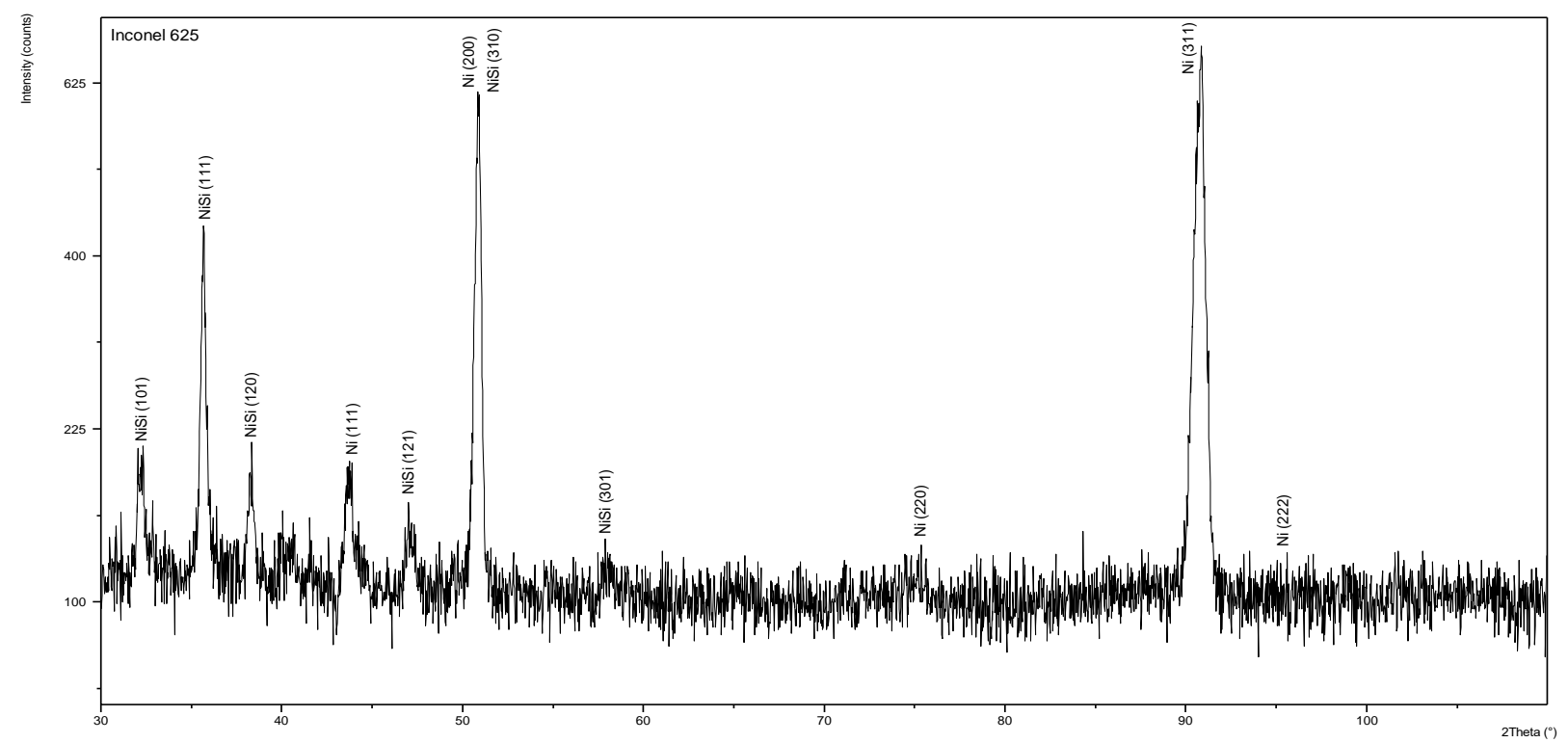

Fig. 7. Examples of X-ray spectrum of overlay weld in the surface of Inconel 625 superalloy layer obtained in the process of plasma powder transferred arc welding (PPTAW), sample 9

\section{Hardness measurement}

The visible depth of the HAZ measured during macroscopic tests for individual samples manufactured by plasma powder transferred arc welding PPTAW method, figure 5, was confirmed by microhardness measurements. The average microhardness result of HV0.3 tested on the cross-section of $16 \mathrm{Mo} 3$ steel pipes covered with the outer layer of an Inconel 625 nickel superalloy plating applied in powder plasma welding technology is presented in table VII. The results are the average of five measurements made every $0.1 \mathrm{~mm}$ in native material, HAZ and the surfaced layer. The native material is characterized by a hardness of approx. 160 $\div 165$ HV0.3, while in the range of applied amount of heat introduced into the native material during the surfacing process, the low presence of martensite in HAZ caused a slight increase in hardness - up to $210 \mathrm{HV} 0.3$. The hardness of the plating layer in the whole range of applied surfacing parameters exceeded $230 \mathrm{HV} 0.3$.

Table VIII. Average microhardness HV0.3 measured on the cross-section of $16 \mathrm{Mo} 3$ steel pipes clad with Inconel 625 superalloy, table VI

\begin{tabular}{|c|c|c|c|c|c|c|c|c|c|}
\hline \multirow{3}{*}{ Place of measurement } & \multicolumn{9}{|c|}{ Sample's designation } \\
\hline & 1 & 2 & 3 & 4 & 5 & 6 & 7 & 8 & 9 \\
\hline & \multicolumn{9}{|c|}{ Average microhardness HV0.3 } \\
\hline Base material (16Mo3) & 161.5 & 165.3 & 163.8 & 162.7 & 162.9 & 163.1 & 162.9 & 161.4 & 160.3 \\
\hline Heat affected zone & 209.8 & 193.4 & 196.4 & 199.2 & 190.5 & 186.1 & 182.2 & 180.3 & 178.8 \\
\hline Plating layer (Inconel 625) & 232.8 & 235.4 & 231.0 & 236.2 & 238.7 & 229.6 & 232.2 & 235.1 & 232.9 \\
\hline
\end{tabular}

\section{Summary}

The scope of research included the development of robotic plasma powder transferred arc welding (PPTAW) technology enabling the production of a plating layer of Inconel 625 nickel superalloy on the external surface of a $16 \mathrm{Mo} 3$ steel pipe. The quality of the protection was assessed based on non-destructive testing, metallographic examination of the microstructure and hardness of the surfaced layer. It has been proven that the surfacing parameters used ensure the metallurgical connection of Inconel 625 nickel superalloy $-16 \mathrm{Mo} 3$ boiler steel without any welding imperfections, with a minimum share of native 
material, a narrow heat affected zone and the required iron content at a plating surface not exceeding $7 \%$. Robotic technology of plasma powder transferred arc welding (PPTAW) has contributed to increased reliability, increased efficiency and repeatability of the process. The thickness of a single layer of the plating produced in the technology of plasma powder surfacing was about half smaller than the surface layer surfaced with the same nickel super alloy by the MIG method [2], while the allowances for finishing treatment of plasma surfaced layers will be small, and thus material losses will be lower. It was found that the developed cladding technology can be successfully used to perform protection on a heat exchanger pipe or other elements operated in similar operating conditions. The results of the research on the effect of aging temperature of the plating layer of Inconel 625 nickel superalloy on corrosion resistance will be published in one of the next issues of the magazine.

Conflicts of Interest: The author declare no conflict of interest.

\section{References}

[1] Dobrzański J., Material science interpretation of steel durability for the power industry, International, Tom 3 Open Access Library, ISSN 2083-5191, OCSCO World Press, 2011.

[2] Golański G., Lachowicz M., Słania J., Jasak J., Marszałek P., Research on 16Mo3 (16M) steel pipes overlaid with Haynes NiCr625 alloy using MIG (131) method, 2015, Archives of Metallurgy and Materials, Vol. 60(4), $2521-2524$. DOI:10.1515/amm-2015-0408 [Hyperlink]

[3] Węgrzyn T., Piwnik J., Low alloy welding with micro-jet cooling, Archives of Metallurgy and Materials, 2012, Vol. 57(2), 540-543. DOI: 10.2478/v10172-012-0056-x [Hyperlink]

[4] Zieliński A., Dobrzański J., Characteristics of changes in properties and structure in X10CrMoVNb9-1 steel due to long-term impact temperatures and stress, Archives of Materials Science and Engineering, 2013, Vol. 60(2), $72-81$.

[5] Uussitalo M.A., Vuoristo P.M.J., Mantyla T.A., High temperature corrosion of coatings and boiler steels in reducing chlorine - containing atmosphere, Surface and Coatings Technology, 2002, Vol. 161(2-3), $275-285$. [CrossRef]

[6] Adamiec J., Kierzak A., Padding of the components of waste combustion boilers with the use nickel alloys, Inżynieria Materiałowa, 2008, Vol. 29(4), 380-385.

[7] Mikułowski B., Heat-resistant alloys - super alloys, AGH Publ., Cracow 1997.

[8] Frei J., Alexandrov B.T., Rethmeier M., Low heat input gas metal arc welding for dissimilar metal weld overlays part I: the heat-affected zone, Welding in the World, 2016, Vol. 60(3), 459-473. [CrossRef]

[9] Frei J., Alexandrov B.T., Rethmeier M., Low heat input gas metal arc welding for dissimilar metal weld overlays part II: the transition zone, Welding in the World, 2018, Vol. 62(2), 317-324. [CrossRef]

[10] Rozmus-Górnikowska M., Blicharski M., Kusiński J., Influence of weld overlaying methods on microstructure and chemical composition of Inconel 625 boiler pipe coatings, Kovove Materialy, 2014, Vol. 52(3), 1-7. DOI: $10.4149 / \mathrm{km} 20143141$

[11] Lippold J.C., Kimur S.D., DuPont J.N., Welding Metallurgy and Weldability of Nickel-Base Alloys, Wiley Publ. 2009.

[12] Adamiec P., Adamiec J., Aspects of pad welding of waste incineration boiler elements with Inconel 625 and 686 alloys, Welding Technology Review, 2006, Vol. 78(5-6), 11-14.

[13] Adamiec J., Surfacing by welding elements of furnace for waste material burning using nickel alloys, in Materials and technology for construction of supercritical boilers and waste planst, ed. A. Hernas, SITPH Publ., 294-315, Katowice 2009.

[14] Rajkumar V., Arjunan T.V., Rajesh Kannan A., Metallurgical and mechanical investigations of Inconel 625 overlay welds produced by GMAW-hardfacing process on AISI 347 pipes, Materials Research Express, 2019 , Vol. 6(7). [CrossRef]

(C) 2019 by the authors. Submitted for possible open access publication under the terms and conditions of the Creative Commons Attribution (CC BY) license (http://creativecommons.org/licenses/by/4.0/). 